\title{
Perspectiva Histórica de Cambio de Paisajes en el Altiplano Andino del Titicaca
}

Historical Perspective of Landscape Transformation in the Andean Altiplano of Titicaca

\author{
Paula Ermila Rivasplata Varillas \\ [rivasplatavarillas@gmail.com]
}

Recibido: 6 de diciembre de 2016

Aprobado: 12 de marzo de 2017

DOI:

Cita sujerida: Rivasplata Varillas, Paula E. "Perspectiva histórica de cambio de paisajes en el

altiplano del Titicaca." HALAC VII, no.1 (junio): 14-27.

\section{RESUMEN}

El Altiplano es un territorio que presenta un proceso de desertización que se ha mantenido constante más allá de las fluctuaciones climáticas desde el final del Pleistoceno Superior y tránsito Pleistoceno-Holoceno. A pesar de estas características tan difíciles para el asentamiento de poblaciones y el desarrollo socioeconómico, se han implantado sociedades con diverso grado de complejidad. Estas sociedades han manejado su medio natural desde tiempos pretéritos de diversas maneras: frágil, estocástica, resiliente 0 adaptativa.

\section{Palabras claves}

Paisaje, Altiplano Andino, Titicaca, Adaptación, Resiliencia, Ruptura, Culturas Precolombinas.

\section{ABSTRACT}

The Altiplano is an area that presents a process of desertification that has remained constant beyond climatic fluctuations since the late Pleistocene and Pleistocene-Holocene transition. Despite these difficult details for the settlement of populations and socioeconomic development, societies have been implemented with varying degrees of complexity. These communities have managed their natural environment since time immemorial in various ways: fragile, stochastic, resilient or adaptive manner.

\section{KEYWORDS}

Landscape, Andean Altiplano; Titicaca, Adaptation, Resiliency, Break, Pre-Columbian Cultures

\section{Introducción}

El hombre se ha encontrado con condiciones naturales de desertización, las cuales ha asumido en forma de asimilación, adaptación a la naturaleza hasta imposición de su impronta sobre ella. En este proceso ha adquirido a través de la observación y experimentación conocimiento sobre las características del altiplano, creando sistemas para convivir con ella, obteniendo de esta manera no sólo cobijo sino también alimentación. Esto es confirmado por los restos arqueológicos encontrados, como las 25.000 unidades de cochas o lagunas artificiales construidas ex profeso para capturar el agua de

\footnotetext{
* Doctora. Profesora de la Universidad Inca Garcilaso de la Vega, Lima, Perú.
} 
Iluvia y así aprovechar el recurso agua tan escaso en la puna, canalizándolo y distribuyéndolo según sus necesidades. ${ }^{1}$

El Altiplano andino ha obligado desde siempre a sus habitantes a tomar todas las medidas necesarias para asegurar la supervivencia en condiciones casi siempre adversas para el ser humano, con fríos intensos, con suelos propensos a la salinidad y, con largos períodos de sequía e inundaciones. En este entorno de desertización, las culturas precolombinas crearon una cosmovisión centralizada en la no trasgresión del equilibrio del entorno natural, logrando superar la economía de subsistencia para llevar a cabo cultivos intensivos que permitieran sostener a su densa población. Pero, también modificaron el paisaje natural a uno antropogénico, transformando el entorno con andenes, camellones destruyendo el ecosistema natural, existiendo casos de sobreexplotación.

También, Iograron crear estrategias para utilizar el ambiente altiplánico para optimizar la productividad. Así, las heladas sirven para deshidratar la papa, logrando el chuño que eran almacenadas en la innumerables pirwas o depósitos diseminados por la puna altiplánica, previendo las temporadas de escasez de alimentos y asegurar su alimentación. Otra estrategia era alternar las técnicas hidráulicas y agrícolas: cochas, camellones (cultivos bajo inundación), andenes (terrazas) y albuferas artificiales para el crecimiento de pastos. ${ }^{2}$

El altiplano andino fue ocupado principalmente por dos culturas precolombinas: Pukara y Tiahuanaco. La cultura Pukara se asentó en el extremo norte del lago Titicaca; mientras que mucho después, otra gran cultura mucho más compleja, la Tiahuanaco se desarrolló en el extremo sur; esta última se orientó hacia el desierto y por lo tanto a su desaparición, la cultura Pucara se emplazó hacia nuevos nichos ecológicos, los Andes y por ende a una multiplicidad de microclimas, siendo más indulgente con el hombre para la obtención de su alimentación que la puna altiplánica, siendo uno de los factores que motivaron el surgimiento de nuevas culturas como la Huari y posteriormente la Inca, dando la espalda al altiplano, alejándose de su núcleo central y matriz. Un ejemplo de una cultura que se aleja de la génesis de su cosmogonía. Así, cada vez fue más intenso el abandono de estas zonas por nuevos nichos que proveía de alimentos más fácilmente obtenidos y no con tanto esfuerzo y menos sujeto al riesgo climático como el Altiplano. En la actualidad, los paisajes altiplánicos relictos son testimonios de los cambios de uso que este espacio ha estado sometido, pasando de una sociedad agropecuaria (Preinca e Inca), ganadera y minera (Colonia) a una eminentemente ganadera (Republica).

La problemática del presente trabajo consiste en comparar el manejo del territorio y sus elementos geoecológicos (flora, fauna y procesos ecológicos) entre diferentes tipos de sociedades. Este trabajo busca comprender cómo un manejo adecuado a la capacidad regenerativa del medio natural y sus recursos, puede controlar las condiciones de desertización del altiplano y al mismo tiempo ser productivo; mientras que un manejo inadecuado puede provocar ruptura definitiva de la resiliencia ambiental-social, por el aumento de la desertización natural debido a la desertificación antropogénica

Los objetivos del presente artículo son detectar el cambio del uso del paisaje según las actividades antropogénicas realizadas en el altiplano. También encontrar las continuidades en el tiempo en la relación hombre-medio natural altiplánico y el cambio del uso del paisaje desde las culturas precolombinas a las comunidades campesinas actuales, a través de las prácticas agrícolas, hidráulicas y tratamiento del territorio en condiciones de desertización. Finalmente, mostrar que un manejo adecuado a la capacidad regenerativa del medio natural y sus recursos, puede controlar las condiciones de desertización del altiplano y al mismo tiempo ser productivo; mientras que otro manejo inadecuado, puede provocar ruptura definitiva de la resiliencia ambiental-social, por el aumento de la desertización natural debido a la desertificación. ${ }^{3}$

\footnotetext{
${ }^{1}$ Clark Erickson, "The Lake Titicaca Basin: A Pre-Columbian built landscape", in Imperfect balance: Landscape transformations in the Precolumbian Americas (New York: Columbia University Press, 2000), 311-56.

2 F. Palacios Ríos, F. "Pastizales de regadío para alpacas", Pastores de Puna (pp. 155- 170). Lima: Instituto de Estudios Peruanos, 1977. Erickson (2000), pp.341-345.

${ }^{3}$ La resiliencia ecológica es entendida como la magnitud de la alteración que puede ser absorbida por un sistema sea social 0 ambiental antes de que se mueva de un estado a otro y la resiliencia social se entiende la capacidad de los grupos 0 comunidades de enfrentar tensiones externas y disturbios.
} 


\section{Perspectiva histórica y arqueológica de cambio de paisajes en el Altiplano Andino del Titicaca}

Esta perspectiva histórica de cambio de paisajes en el altiplano andino que presento trata de comprender el grado de resiliencia de las sociedades, por la presión humana sobre la naturaleza altiplánica y por las fluctuaciones geoambientales. Esta presión social sobre la naturaleza produce una reacción de diverso grado que puede ser asimilada por la sociedad o resquebrajarla ante oscilaciones climáticas severas. Llegando a la conclusión que sociedades más diversas, fragmentadas, pequeñas y complementarias como la cultura Pukara son mucho más resilientes 0 elásticas ante oscilaciones climáticas severas que sociedades más unitarias, grandes y potentes como la cultura Tiahuanaco.

El entorno altiplánico ha sostenido sociedades pequeñas y medianas, que no han ejercido demasiada presión al sistema natural, como los estados locales tipo Pukara. Caso contrario ocurre si sustenta sociedades de carácter imperial como Tiahuanaco o Inca, muy demandantes en recursos naturales, no sólo para abastecimiento propio sino para generar excedentes con fines de expansión militar, social y económica. Sociedades muy complejas con densa demografía que exigen altas productividades agrícolas de forma intensiva, generando sobreexplotación y presión del medio natural que, ante cualquier oscilación climática severa, provoca, a su vez, fragmentación y éxodo de la sociedad.

Teniendo en cuenta lo anterior, me atrevo a proponer la siguiente hipótesis: Un manejo adecuado de la capacidad regenerativa del medio natural y sus recursos puede controlar las condiciones de desertificación del altiplano y al mismo tiempo ser productivo; mientras que un manejo inadecuado podría provocar la ruptura definitiva del sistema natural.

Tabla 1- Cambio paisajístico en el altiplano andino del Titicaca

\begin{tabular}{|c|c|c|}
\hline Fases cronológicas & Uso del espacio & Paisajes característicos \\
\hline $\begin{array}{l}\text { Fase 1: Aclimatación (10.000 a.C-1.500 } \\
\text { a.C.) }\end{array}$ & $\begin{array}{l}\text { Pescadores - cazadores - recolecores } \\
\text { (Lítico) }\end{array}$ & $\begin{array}{lll}\begin{array}{l}\text { Paisaje en proceso de } \\
\text { domesticación }\end{array} & \\
\end{array}$ \\
\hline $\begin{array}{l}\text { Fase 2: Adaptacion socionatural ( } 1.500 \\
\text { a.C.-500 d.C.) }\end{array}$ & $\begin{array}{l}\text { Sedentarizacion e inicio de la agricultura } \\
\text { (Arcaico) Cultura Pukara }\end{array}$ & $\begin{array}{l}\text { Paisaje agrícola irrigado con aguas } \\
\text { pluviales y lacustres (Cochas y } \\
\text { Camellones) }\end{array}$ \\
\hline $\begin{array}{l}\text { Fase 3: Suplantación (500 d.C.-1.100 } \\
\text { d.C.) }\end{array}$ & $\begin{array}{l}\text { Sociedades complejas } \quad \text { (Cultura } \\
\text { Tiahuanaco) }\end{array}$ & $\begin{array}{l}\text { Paisaje con agricultura y ganadería } \\
\text { a gran escala e intensiva y con } \\
\text { grandes construcciones en piedra }\end{array}$ \\
\hline $\begin{array}{l}\text { Fase } 4 \text { : Ajuste y asimilación (1.100 d.C.- } \\
1.533 \text { d.C.) }\end{array}$ & $\begin{array}{l}\text { Manejo y control de los espacios } \\
\text { geograficos (Jefaturas y Cultura Inca) }\end{array}$ & $\begin{array}{l}\text { Paisaje con pastizales y extensas } \\
\text { terrazas de cultivo (andenerías) }\end{array}$ \\
\hline Fase 5: Ruptura (1.533 d.C. -1.821 d.C.) & $\begin{array}{l}\text { Imposicion foránea al uso del espacio } \\
\text { (Colonia Española) }\end{array}$ & $\begin{array}{l}\text { Paisajes coloniales de pastizales con } \\
\text { ganado alóctono, de zonas mineras } \\
\text { y de grandes ciudades alrededor del } \\
\text { lago Titicaca }\end{array}$ \\
\hline $\begin{array}{l}\text { Fase 6: Apropiación y mixtura } \\
\text { (1.821 d.C. a la actualidad). }\end{array}$ & Mestizaje (República) & $\begin{array}{l}\text { Paisaje de pastizales, ciudades, } \\
\text { desertificación y contaminación. } \\
\text { Paisajes de ciudades, monocultivos, } \\
\text { desertificación, contaminación. } \\
\text { Impulso a la agricultura tradicional }\end{array}$ \\
\hline
\end{tabular}

Fuente: Elaboración Propia.

\section{Fase 1: Aclimatación (10.000 a.C-1.500 a.C.) pescadores - cazadores - recolectores: paisaje en proceso de domesticación}

Los cambios climáticos afectaron considerablemente a los grandes animales que moraban el altiplano andino. Hacia 12.000 años a.C., desapareció la fauna propia de la época y aparecieron nuevas especies como el guanaco y la vicuña, descendientes del paleolama. Se inicia el periodo llamado Holoceno o Post-Glacial que sigue al Pleistoceno

Durante este periodo, desde el punto de vista climático las variaciones fueron intensas, pasando de etapas húmedas a secas y viceversa. El final del pleistoceno y comienzos del Holoceno se caracterizó 
por Iluvias intensas, hasta aproximadamente 7.500 años a.C. Posteriormente, el lago Titicaca registró descenso del nivel de sus aguas, llegando a 50 metros bajo el nivel actual.

Entre 5.700 a 5.250 a.C., el Titicaca se caracterizó por cuencas individualizadas muy poco profundas, pequeñas y espaciadas debido al fuerte periodo de desecación, reduciéndose el $42 \%$ de la superficie del lago y una pérdida del $30 \%$ de su volumen del agua. La comunicación entre el Lago Mayor y el Lago Menor estaban cortadas. ${ }^{4}$

De 5.250 a 2.000 a. C continúa el periodo seco deducido por la concentración de ostrácodos y asociaciones de diatomeas. Pero, a partir del 2.000 a.C. se produce un aumento progresivo del nivel del agua. Se produce una mejoría climática planetaria, trocando al ambiente mucho más húmedo. Aumentan las lluvias, que vuelven dulces las aguas del Lago Titicaca y se restablece la conexión entre lago mayor y menor.

Desde el punto de vista antropogénico, los cazadores, recolectores y pescadores empezaron a establecerse por primera vez a lo largo del Altiplano en torno a 10.000 a.C. Pero la ocupación de la zona propiamente dicha se pudo haber dado cuando se alcanzaron los niveles máximos del agua en el lago Titicaca entre los 8.800 a.C. a 7.200 a.C. ${ }^{5}$ cuando elaboraban finos instrumentos de piedra como puntas de proyectil y ocupaban las cuevas altoandinas, especializándose en la caza de camélidos y en la recolección de raíces y tubérculos propios de la zona. Las condiciones climáticas húmedas se fueron haciendo más secas paulatinamente al final de la fase. Los recursos hídricos y naturales se redujeron, obligando a la gente a modificar las estrategias sociales de supervivencia y a buscar refugios ecológicos, que eran lugares puntuales de ocupaciones nómadas dentro del ambiente altiplánico. ${ }^{6}$

Entre el 6.000 a. C. a 1.600 a.C. se intensificaron los cambios climáticos a condiciones más áridas, motivando ocupaciones excepcionales en ecorefugios de fauna y de predadores humanos, produciéndose una reducción en la disponibilidad de los recursos durante la ocupación humana preagrícola y preirrigadora. La obtención de alimentos se logra a través de la recolección selectiva y racional que consistía en la diferenciación de semillas y plantas. Con esto se va llegando a una agricultura incipiente, cuyo inicio se produce hacia los 6.000 a.C. Esta incipiente agricultura y también el pastoreo pudieron empezar a causar, según algunos investigadores, ciertos procesos de deforestación, erosión y desertificación.

Las duras condiciones medio ambientales y de estrés hídrico en una región con recursos naturales marginales pudieron tener como resultado la despoblación del área o bien desencadenar interesantes procesos adaptativos de toda índole, incluso de carácter tecnológico. El mayor grado de desertización se dio entre 5.000 a.C. y 4.000 a.C., luego el clima altiplánico fue de nuevo tornándose más húmedo.

En este periodo, las comunidades cazadoras y recolectoras prehistóricas fueron adoptando un modelo sedentario, estableciéndose cerca de algunas fuentes de agua perennes, donde el proceso de domesticación de camélidos empezó alrededor del 3.000 - 2.000 a.C. ${ }^{7}$ Un total de 240 sitios arqueológicos del periodo precerámico (6.000 y 1.500 a.C.) se han encontrado a lo largo del río llave en el noroeste del altiplano andino, y no en las cercanías al lago Titicaca porque no ofrecía las condiciones para su ocupación debido a las severas sequías crónicas y a su bajo nivel de aguas. Además, las riberas del lago Titicaca estaban cubiertas de bosques nativos de Polylepis spp., de los que, aún hoy, se mantienen restos de árboles relictos. ${ }^{8}$

En el altiplano andino, el accionar de los primeros hombres sobre la naturaleza en el Holoceno se dio a través de la caza, pesca, recolección, deforestación y el fuego. Estas zonas húmedas fueron "conquistadas "por los cazadores, pescadores y recolectores holocénicos a base de quemas regulares

\footnotetext{
${ }^{4}$ Denis Wirrmann, Jean -Pierre Ybert, e Philippe Mourguiart, "Morfología y batimetría", in Lago Titicaca: Síntesis del conocimiento limnologico actual (La Paz: ORSTOM, 1991), 49-66.

${ }^{5}$ Bruno Messerli et al., "From nature-dominated to human-dominated environmental changes", Quaternary Science Review 19, no 1-5 (2000), 459-79, https://doi.org/https://doi.org/10.1016/S0277-3791(99)00075-X.

6 Hugo Yacobaccio y Marcelo Morales, "Mid-Holocene environment and human occupation of the Puna", Quarternary International 132, núm. 1 (2005): 5-14, https://doi.org/https://doi.org/10.1016/i.quaint.2004.07.010.

7 Erickson (2000), 321.

8 Erickson (2000), 319-320.
} 
de árboles y arbustos nativos para facilitar la caza y la recolección; y para acceder a las orillas del lago Titicaca y plantar totora, con la que fabricar embarcaciones para el transporte fluvial. Se han encontrado restos de carbón con datación de 4.000 a.C. ${ }^{9}$ El proceso de transformación de cazadores, recolectores y pescadores del Arcaico temprano a sociedades complejas fue un proceso muy lento.

\section{Fase 2: Adaptación socionatural (1.500 a.C.-500 d.C.) - Cultura Pukara: paisaje agrícola irrigado con aguas pluviales y lacustres}

La iniciación de la agricultura intensiva y la aparición de sociedades complejas cerca al lago Titicaca coincidió con un nuevo aumento considerable de la humedad, hacia 1.500 a.C., que causó la subida de 20 metros en el nivel de aguas del lago Titicaca, según datos obtenidos de los sedimentos del lago y estudios de los glaciares colindantes.

Tal aumento de la humedad, constatado desde 1.500 a.C., tiende a establecer las características lacustres actuales y conduce a cambios hacia condiciones climáticas más favorables a las actividades humanas. Ello permite el desarrollo de métodos de agricultura especializada que estimularon el crecimiento poblacional y el desarrollo de civilizaciones. Se crean las condiciones medioambientales para el desarrollo de la agricultura intensiva aproximadamente en el 1.500 a. C. y de la agricultura bajo irrigación desde cerca de 1.100 a.C. ${ }^{10}$ Aproximadamente a 1.000 a.C., los agricultores empezaron a construir camellones o terrazas de cultivo bajo inundación en la cuenca norte del lago Titicaca. Mientras que los andenes o terrazas de plataforma se empezaron a utilizar más tardíamente, en el $200 \mathrm{a}$. C. Se comienza a practicar una agricultura con terrazas y canales de irrigación dentro de un proceso de adaptación lenta, pero el rango de innovaciones tecnológicas parece bastante alto en un medio ambiente muy hostil por su stress hídrico.

Los cambios medioambientales oscilaron entre áridos extremos con algunos periodos húmedos de tal manera que en esta fase el ser humano tuvo que elegir entre defenderse, adaptarse 0 emigrar. ${ }^{11}$ Pero, como ya se ha visto, hacia el 1.200 a.C. se ha constatado una recuperación estructural del régimen de humedad, con el alza de los niveles lacustres y el inicio de labores complejas agrícolas y pastorales bajo condiciones ambientales más análogas a las actuales. ${ }^{12}$

Esta fase es principalmente agropecuaria, destacando el desarrollo de estrategias agrícolas (cochas, camellones, bofedales, andenes) para superar los riesgos climáticos severos del altiplano andino. Se produce un aumento demográfico y un progresivo control territorial de los distintos espacios geográficos - el lago, los valles, las pampas del altiplano y las áreas de pastizal - donde se van implantando sistemas productivos. Precisamente, la utilización de aquellos ecosistemas de forma adaptativa y complementaria coincide con la génesis de la complejización de la sociedad en el altiplano.

Todo este bagaje de conocimientos fue heredado y perfeccionado por muchas civilizaciones durante este periodo de adaptación, pero entre todas destaca la cultura precolombina llamada Pukara. Se han identificado más de 34 sitios arqueológicos Pukara (500 a.C-400 d.C) en el norte del lago Titicaca, no sólo ocupó el lago y la puna, sino siguió los cursos de los ríos Pukara y Azangaro, hacia Lampa y Sicuani cerca de los valles interandinos quechuas del Cuzco. De tal manera que desbordaron los límites del altiplano, dirigiéndose hacia cuencas de los Andes centrales (Carabaya, Vilcanota, Apurimac). La cultura Pukara se amplió hacia otras zonas para obtener recursos complementarios como los provenientes de la costa del Océano 8Pacifico (valle de Azapa) o de los valles interandinos citados, teniendo acceso a nichos ecológicos no usados anteriormente. Esto les condujo a ejercer el control

\footnotetext{
${ }^{9}$ Michael W. Binford et al., "Climate variation and the rise and fall of an Andean civilization", Quaternary Research 47, núm. 2 (1997), 235-48, https://doi.org/https://doi.org/10.1006/qres.1997.1882.

${ }^{10}$ Binford et al, 235.

${ }^{11}$ Messerli et al, 465.

12 Lautaro Núñez, Martin Grosjean, y Isabel Cartajena, "Human dimensions of late Pleistocene/Holocene arid events in southern South America”, en Vera Markgraf (ed.) Interhemispheric Climate Linkages (Oxford: Elsevier, 2001), 105-17.
} 
territorial interno, relacionando tres sistemas productivos altiplánicos: los recursos del lago y de sus islas, la agricultura de altura y los pastos para los camélidos. Así, la sociedad Pukara marcó el inicio del surgimiento de sociedades complejas en la cuenca del Titicaca ${ }^{13}$

En estos sitios arqueológicos Pukara no sólo se desarrollaron actividades agrícolas y ganaderas autosuficientes, sino también el comercio, la cerámica y la textilería, la escultura y la arquitectura con grandes centros urbanos líticos. Pero, la agricultura se convirtió en la actividad principal basada en una economía de subsistencia. Era una sociedad eminentemente agrícola, con tecnologías propias y adecuadas a las características de su medio ambiente, de su geografía y su edafología. Crearon un paisaje agrícola que aún se mantiene y se continúa practicando en la actualidad, las más grandes concentraciones de cochas o lagunas artificiales preexistentes fueron hechas por pobladores de la cultura precolombina Pukara. ${ }^{14}$

En cuanto a la ganadería, considerada actividad complementaria de la agricultura, se basaba en las alpacas, pero también utilizaba las llamas como especie de reserva para las épocas de sequía, heladas y otras calamidades. ${ }^{15}$ La adopción de la ganadería y la agricultura debe haber causado una permanente modificación en los paisajes de la zona de estudio. Se trató de superar el límite de crecimiento de algunas plantas por la altura y el frío, a través de la selección de semillas, de experimentación, de observación, de ensayo y error, logrando cultivar papa y cañigua hasta los 4.450 m.s.n.m. En función de ello, algunos autores como Erickson afirman que no sólo lograron la adaptación sino también la transformación de la naturaleza a través de sus técnicas agrícolas productivas.

El paisaje dominante de esta cultura Pukara y de toda la segunda fase sería el de la agricultura de irrigación con aguas pluviales y lacustres. Los ecosistemas naturales fueron suficientemente resilientes a los posibles impactos de la sociedad Pukara. Por su parte, el sistema social creado fue también resiliente y superó las oscilaciones climáticas con sus tecnologías agrícolas. La sociedad Pukara se fortaleció, convirtiéndose en un ejemplo de sociedad adaptada a su medio natural

\section{Fase 3: Suplantación (500 d.C.-1.100 d.C.) - Cultura Tiahuanaco: paisaje con agricultura y ganadería a gran escala e intensiva y con grandes construcciones en piedra}

El aumento poblacional y las exigencias propias de una sociedad en expansión, fueron diseñando un paisaje con grandes construcciones en piedra, con sobreexplotación de recursos naturales, presión a los ecosistemas por la práctica de una agricultura y ganadería intensiva. La imposición de unas redes de poblamiento jerarquizadas y del aumento de producción -debido a la necesidad de generar amplios excedentes, que carecían de sentido en las comunidades campesinas tipo Pukara - fueron exigencias de una sociedad imperial tiahunacoide, con nuevas formas de organización social.

En el noroeste del altiplano, las sociedades indígenas de autosubsistencia se ven insertas en la nueva sociedad surgida bajo el dominio de Tiahuanaco. No obstante, se mantienen los sistemas productivos de pueblos como el Pukara durante la ocupación tiahuanacoide, porque son efectivos para proporcionar avituallamiento y excedentes a la exigente sociedad Tiahuanaco, que trata de hacerse visible fundamentalmente por medio de construcciones megalíticas y por la obtención de producciones excedentes para sus expansiones militares, consumiendo gran cantidad de mano de obra y de alimentos.

Parece, pues, que el comienzo de una sobre explotación de los recursos en esta fase está justificado por asuntos religiosos -"el acceso a los recursos, el control de los medios de producción, la distribución de la fuerza de trabajo y la organización del desarrollo de estos últimos, así como la

\footnotetext{
${ }^{13}$ Elias Mujica Barreda, "Altiplano-coast Relationships in the South- Central Andes: From Indirect to Direct Complementary" en Shozo Masuda, Izumi Shimada, Craig Morris (eds.) Andean Ecology and Civilization. An interdisciplinary Perspective on Andean Ecological Complementary. (Tokyo: University of Tokyo Press, 1985), 123-128.

${ }^{14}$ Erickson, 337.

${ }^{15}$ John Murra, "Una apreciación etnológica de la visita". Visita hecha a la Provincia de Chuchito por Garci Diez de San Miguel en el año 1567.(Lima: Ediciones de la Casa de la Cultura del Perú, 1964), 423.
} 
determinación de la forma social de la circulación y de la redistribución de los productos del trabajo individual o colectivo, es decir las relaciones de producción estuvieron determinadas por la actividad religiosa", ${ }^{16}$ pero también por la expansión territorial, por el aumento poblacional y por la formación de Estados centralizados. Todos aquellos factores determinaron el control de múltiples niveles ecológicos en los Andes del sur.

Tiahuanaco se desarrolló en la puna seca sur y se orientó hacia territorios en proceso de desertización natural, aunque se abasteció de productos de otros ecosistemas lejanos. Necesitó establecer mecanismos de dominación y control de la población para ejercer su dominio sobre colonias agrícolas productoras de coca en los valles de la vertiente oriental andina y productoras de maíz y de ají en los valles templados de la vertiente occidental andina. Así, se establecieron colonias de explotación en diferentes ecosistemas para proveerse de productos como el maíz, la coca, los frutos del mar y los minerales que fueron asequibles desde largas distancias. Aunque, las culturas más tempranas, como la Pukara, ya los adquirían a través del comercio o trueque, los tiahuanacos los adquieren por explotación colonial directa, asegurándose el acceso a los recursos necesarios para su manutención. ${ }^{17}$

Construcciones arquitectónicas implican mayor mano de obra, y tal incremento poblacional de los centros urbanos de Tiahuanaco crea la necesidad apremiante de extender la cantidad de campos de cultivo elevados alrededor del Lago Titicaca para alimentar a la población no rural. Esta demanda -de carácter estatal- intensifica la tecnología de los waru waru 0 camellones. ${ }^{18}$ En función de tales procesos, la cultura Tiahuanaco no sólo fue controlando todos los recursos y sobredimensionando las producciones de su propia área nuclear -alrededores del lago, islas lacustres, puna y cerros colindantessino que también fue ocupando y explotando ecosistemas naturales complementarios -como valles interandinos, vertiente oriental y occidental de los Andes y litoral- a través de colonias de explotación.

Pero, como todo sistema jerarquizado e imperial, el sistema sociocultural Tiahuanaco no fue suficientemente resiliente ante las fluctuaciones climáticas y se fragmentó ante una perturbación climática severa que fue la llamada crisis climática seca, ocurrida aproximadamente en el año 1000 d.C. De manera que, el final de esta fase se caracteriza por ser una época de cambios, según algunas evidencias arqueológicas y la modificación de los motivos religiosos que aparecen en la cerámica. Entre 1.100-1.200 d.C., Tiahuanaco termina abruptamente. ${ }^{19}$ Un probable colapso agrario masivo que pudo haber sido consecuencia de la desintegración política del imperio por haber superado la capacidad de resiliencia del ecosistema natural y cuya detonante fue la crisis climática seca. El imperio se fragmentó en pequeños gobiernos regionales: Pakaq, Lupaza, Qolla y otros. La autoridad central se parte y quedan dispersados sus elementos constituyentes.

\section{Fase 4: Ajuste y asimilación (1.100 d.C.-1.533 d.C.) - Jefaturas y cultura Inka: paisaje con pastizales y terrazas de cultivo}

Ante el colapso agrario, la cultura Tiahuanaco se fragmentó, formándose señoríos o jefaturas. Los collas, propiamente dichos, estaban situados en la parte noroeste del lago Titicaca, regada por los ríos Pukara y Ramis, y su capital era Hatuncolla. En la parte sudoeste del Lago hasta el río Desaguadero se encontraban los lupacas, cuya población principal era Chuchito. Los señoríos post-Tiahuanaco, en el periodo Intermedio Tardío, se dispersan en pequeños pueblos aymarâs unidos por vínculos de

\footnotetext{
${ }^{16}$ Anne M. Hocquenghem, "Como una imagen del otro lado del espejo. Memoria para el futuro: una visión del orden del mundo andino", Pensar América. Cosmovisión Mesoamericana y andina. (Córdoba: Obra social y cultural Caja Sur. Ayuntamiento de Montilla, 1997), 221.

${ }^{17}$ Mújica Barreda, 102.

${ }^{18}$ Camellones o Waru-Waru: parcelas de cultivos elevados bajo inundación.

${ }^{19}$ Alan Kolata, "Tiwanaku and Its Hinterland", Archeology 40, núm. 1 (1987), 41.
} 
parentesco y no burocrático, formándose diversos grupos o pequeños poblados más 0 menos independientes; y ligeros rasgos de orden cultural y lingüístico diferenciaban sus poblaciones. ${ }^{20}$

El periodo siguiente de la caída política del Tiahuanaco puede ser caracterizado como el tiempo en que los segmentos rurales de la sociedad obtienen un poder relativo, a través de la satisfacción de las necesidades alimentarias. ${ }^{21}$ Para lograrlo, buscaron nuevas conductas económicas de supervivencia en concordancia con el sistema natural o retornaron a las técnicas ancestrales que consideraron adecuadas.

Los camellones y otras prácticas de agricultura intensiva fueron abandonadas después del colapso del estado Tiahuanaco, debido a la crisis ecológica que produjo la caída de la autoridad central, junto a la cual cayó la organización y dirección humana y material que llevaba a cabo este tipo de agricultura a gran escala. ${ }^{22}$ Estas áreas de cultivo quedaron abandonadas, no siendo retomadas por los inkas, ${ }^{23}$ aunque sí por las sociedades que permanecieron en el lugar, pero como agricultura de subsistencia. También, se produce un creciente desarrollo de las actividades pastoriles en la zona. Así por ejemplo, la cultura colla, en el oeste del lago Titicaca, desarrolló una reputación a lo largo de los Andes de ganaderos, controlando vastos rebaños de llamas y alpacas. Cuando el estado inka expandió sus fronteras, muchas de las llamas de esta cultura fueron confiscadas como rebaño estatal inka. ${ }^{24}$

La agricultura intensiva fue quedando de lado, pues la disminución poblacional urbana no justificaba el desarrollo de tal tipo de agricultura. Ante el colapso ecológico, primero cayeron las colonias "archipiélago" de la costa, luego las zonas urbanas de la matriz altiplánica, permaneciendo sólo las zonas rurales. Durante la cultura Tiahuanaco, los camellones habían servido para abastecer a los múltiples conglomerados urbanos que rodeaban el lago, pero no fueron utilizados por los inkas como explotación estatal, permaneciendo como agricultura marginal y de subsistencia, que era llevada a cabo por medio de labores reciprocas de carácter comunal. Lo mismo ocurrió con las cochas. Esto fue debido a que en esta fase se produjo un periodo de ajuste y asimilación por las sociedades aymaras, retomando los tipos de agricultura más adecuados a la geografía y altitud, de tal manera que los modos de producción fueron reestructurados y redefinidos desde aquel contexto estatal a uno de economía rural de subsistencia y sin superar la capacidad de carga de los ecosistemas.

Las evidencias arqueológicas demuestran que la construcción y mantenimiento de campos de cultivo a modo de camellones en la cuenca del lago Titicaca no terminó con el colapso del estado Tiahuanaco. Estudios realizados en Pampa Koani establecieron que hubo una fase de extensiva construcción de camellones, que había empezado después del colapso de Tiahuanaco y el inicio del Periodo Intermedio Tardío. ${ }^{25}$

En la época inmediatamente pre-inka, antes del año de 1.436 de nuestra era, durante el Intermedio Tardío, los distintos pueblos aymaras no vivían en la orilla del lago, sino en territorios altos y protegidos, pero tenían cultivos y pastizales en sitios estratégicos, como alrededor de los lagos o fuentes de agua. Fue un periodo caracterizado por intensas guerras pero también de interacción entre las diferentes etnias. ${ }^{26}$

Las "batallas" entre "señores y reyes" se realizaba dentro de una misma etnia o pueblo y estarían vinculadas a la organización dual que estructuraba toda la sociedad aymara, identificando a los aliados y enemigos de cada grupo para equilibrarlos entre un mismo grupo étnico 0 entre varios:

\footnotetext{
${ }^{20}$ José M. Casassas Canto, Las poblaciones prehispánicas del altiplano Perú - Boliviano, Puna y Vertiente Oriental Andina. (Antofagasta: Universidad del Norte, 1977), 333.

${ }^{21}$ Gray Graffam, "Beyond State Collapse: Rural History, Raised Fields, and Pastoralism in the South Andes", American Anthropologist 94(4) (1992), 882-904.

${ }^{22}$ Alan Kolata, "The agricultural Foundations of the Tiawanaku State: A view from the Heartland", American Antiquity 5(4) (1986), 748-762.

${ }^{23}$ Los inkas habían encontrado en los Andes centrales la diversidad biológica deseada y en el altiplano andino impusieron los andenes para el cultivo del maíz fundamentalmente, ya que era considerado alimento sagrado inka.

${ }^{24}$ John Murra, "Herds and herders in the Inca state", Man, culture and animals (1965), 185-215, A. Leeds and A. P. Vayda, eds. Publications núm. 78 of the American Association for the Advancement of Science. Washington, D.C.

${ }^{25}$ Graffam (1992), 893-896.

${ }^{26}$ Felipe G. Poma de Ayala, Primera nueva crónica y buen gobierno (Mexico: Siglo XXI, 1980), 50-52.
} 
Ios Alasaya y los Majasaya de los diferentes grupos étnicos de la franja transversal vivían intercalados de tal manera de que en cada localidad se encontrarían representantes de cada mitad, constituyéndose cada uno en un "freno" institucionalizado sobre las pretensiones expansivas del otro. El cuadro resultante nos muestra una multitud de tensiones locales, cuya expresión bélica no puede sino recordarnos las batallas rituales, ampliamente difundidas en la región surandina, (que se mantienen aun vigentes) en el territorio de Macha, y Puquta y otros grandes grupos étnicos que antiguamente pertenecían a las confederaciones de los Qharaqhara y los Charka. $^{27}$

Son sociedades segmentadas dualmente en forma sucesiva desde la primera desmembración. Algunas de estas peleas pueden ser rituales o para solucionar problemas pendientes para llegar al equilibrio y armonía. Pero muchas veces se rebasa este estado y existe un vencedor. Esta etapa ha sido corroborada por los arqueólogos, quienes en sus excavaciones han descubierto que, entre el estado Tiahuanaco y el estado Inka, los pueblos aymaras diseminados por el altiplano, construyeron fortalezas amuralladas en las cumbres de las colinas. ${ }^{28}$

Estos ejemplos de segmentaciones duales y enfrentamientos rituales como procesos controladores y, paradójicamente, creadores de tolerancia no sólo se producen entre las etnias aymaras en la periferia, en los valles y en las zonas de cultivo, sino que también se han constatado en una de las etnias más estudiadas: Ios Lupaca que vivían en las alturas, más allá de los 4.000 metros sobre el nivel del mar, en la parte occidental del lago, en asentamientos amurallados, que encerraban hasta 60 hectáreas de andenes de cultivo, corrales para auquénidos, chullpas funerarias, viviendas. Pero, continuaban practicando la complementarización vertical a modo de archipiélagos como otras etnias (Jatun Qulla, Pakasa), a través de desplazamientos que se realizaban en determinadas épocas del año y según el calendario agrícola local en los valles de la costa 0 en los valles de la selva alta amazónica, accediendo a algunos de sus recursos. ${ }^{29}$

El estado inka utilizó el altiplano principalmente para la ganadería de camélidos sudamericanos considerados de importancia estratégica, pues significaban alimento, fuente de transporte, objeto de sacrificio, de regalo y de fuente de reserva proteínica a través del charqui o carne seca que se podía conservar largo tiempo en las colcas o almacenes. Existían grupos humanos, dispersos en la zona altiplánica y agrupados en jefaturas, que practicaban una agricultura de subsistencia, pero al invadir e instalarse el estado inka en la zona del altiplano se valió de la organización existente y no la alteró, aunque desde entonces todos los recursos estratégicos pertenecían al estado inka. Con la intromisión inka, los collas u hombres del altiplano tuvieron que trabajar no sólo para su jefe local sino también para la nueva comunidad superior. Estos dominaron la parte norte y oeste y este del lago Titicaca, en donde impusieron el quechua, pero no se consolidaron por el sur del altiplano andino.

Los inkas lograron entender la importancia de los diferentes pisos ecológicos. Así, el altiplano frío y húmedo del noroeste era propio para la crianza de camélidos y a eso lo orientaron, no realizando allí una agricultura a gran escala, sino sólo la necesaria para la subsistencia de los grupos humanos asentados en el lugar. No querían gastar más energías de las necesarias, pues sabían que existían otros pisos ecológicos que les proveerían de las reservas nutricias que necesitasen. Reubicaron a ciertos grupos étnicos aliados en las orillas del lago, a 3.800 metros y cerca del camino real, otorgándoles con ello una señal de confianza. Esto sucedió con los lupacas, quienes dejaron sus antiguos establecimientos en las cimas de los cerros y las tumbas o chullpas. Pero, las relaciones de dominación y subordinación

\footnotetext{
${ }^{27}$ Tristán Platt, El Pensamiento político aymara. Raíces de América. In Albo Xavier (ed.) El mundo Aymara (Barcelona: Alianza, 1988), 392.

${ }^{28}$ Platt, 373.

${ }^{29}$ Platt, 392-393.
} 
entre el Tawantinsuyo y los señoríos aymaras eran oscilantes y algunas veces se sublevaron con el objeto de recuperar los camélidos y las tierras de cultivo, apropiados por el estado inka. ${ }^{30}$

Por otro lado, se produjo un aumento poblacional por la llegada de los mitimaes, que fueron traídos por los inkas de zonas muy lejanas como Quito a las orillas del lago Titicaca, lo que motivó la construcción de mayores andenes, técnica de cultivo que fue la preferida, dejando de lado a los camellones aymaras. ${ }^{31}$

La nueva distribución poblacional inka en el altiplano estaba constituida, pues, por unos pueblos de confianza alrededor del lago, destinados por largas temporadas, por ejemplo, a la frontera norte, siendo excusados de las mitas agrarias y la construcción de caminos en el altiplano y por unas etnias belicosas en sus lugares de origen en las alturas y en las punas.

Este Estado y toda su población preferían cada vez más avocarse a la ganadería y basar su economía y subsistencia en ella, pues representaba menos riesgo de pérdida por las fluctuaciones climáticas y era más fácilmente intercambiable. De manera que, en el Altiplano andino, la economía inka se desarrolló en torno a los camélidos sudamericanos o auquénidos, que constituyeron la principal forma de riqueza individual y estatal. ${ }^{32}$ Esta actividad permitía satisfacer las necesidades de transporte que hicieron posible la construcción de templos, proyectos de irrigación, carreteras, expansión militar, comercio de alimentos, y la minería. Cientos de miles de llamas fueron empleadas en las minas y frecuentes recuas de llamas fueron enviadas a la costa y a la selva alta para el transporte de lana, papa, coca, charki, sal y productos marinos. En cuanto a la conservación de estos animales se practicaron tanto la búsqueda de mejoras genéticas, como los sistemas de rotación de pastos o de crianza selectiva y la prohibición de la caza indiscriminada, para proteger a la vicuña, cuya lana era propiedad del inka. Las cazas periódicas o chacos eran llevadas a cabo cada 3 a 5 años, así como los periodos de trasquila de la lana. Al llegar los españoles, encontraron un gran número de llamas y alpacas, que bordeaba las decenas de millones de animales. ${ }^{33}$ En los cambios de paisaje se hizo evidente este progresivo predominio de la ganadería sobre la agricultura, de manera que se volvió eminentemente a los pastizales.

Al leer las crónicas de la primera época colonial, parece clara la importancia que en el incanato se concedía al medio ambiente climático y su relación con el ser humano. En el conjunto andino, se tiende a ubicar a cada grupo humano dentro de un determinado clima, destacando para ello -entre todos los posibles indicadores climáticos- el criterio de la temperatura. Así pueden quedar catalogadas: la zona fría (el altiplano) habitada por los collas 0 aymaras; la zona intermedia (los valles interandinos) habitada por los quechuas, y las tierras calientes (la amazonía y la costa) habitada por los yungas. Esta vinculación entre cultura humana y medio ambiente había sido ya un criterio muy remoto y generalizado en el Antiguo Perú y durante la ocupación inka del altiplano se continuó utilizando la complementariedad yunga (valles costeros y bosques amazónicos) y quechua (valles interandinos) para sobrevivir y completar sus dietas. $^{34}$

\section{Fase 5: Ruptura (1.533 d.C.-1.821d.C.) Colonia española: paisajes coloniales de pastizales con ganado alóctono, minería y grandes ciudades alrededor del lago Titicaca}

Cuando llegaron los europeos a la parte norte de la cuenca del Titicaca ya era zona de pastos, ${ }^{35}$ por lo que -durante la ocupación europea en los siglos XVI, XVII, XVIII y parte del XIX- el paisaje altiplánico se consolidó como eminentemente ganadero y los usos del suelo se orientaron especialmente a pastizales.

\footnotetext{
${ }^{30}$ John Murra, 55-56.

${ }^{31}$ Murra, 56.

${ }^{32}$ William Franklin, "Biology, Ecology and relationship to man of the South American Camelids", Special publication pymatuning Laboratory of Ecology. (1982), 457-489.

${ }^{33}$ Franklin, 467.

${ }^{34}$ M.M. Valle Yunga, Quechua y Kolla. 1956, Criterio de la Raza en el Imperio Inca. Editorial Lumen. S.A., Impreso. Los inkas entendían la importancia del clima y la temperatura en la vida humana por eso colonizaban otras regiones con gente de parecidas características climáticas(los mitimaes).-

${ }^{35}$ Erickson, 321.
} 
La agricultura fue de subsistencia y la mano de obra indígena fue dirigida eminentemente hacia las actividades mineras. Se introdujo otro tipo de ganadería: el ganado ovino que se expandió exitosamente en este medio, logrando competir con los auquénidos y proveyendo de materia prima para los abastecimientos alimentarios e indumentarios. Así, en el paisaje altiplánico, desde el siglo XVI, no sólo se visualizan los camélidos sino también las ovejas.

Se produce la definitiva conversión del paisaje agrícola de tierra de secano y regadío a uno en el que predominan los pastizales, algún monocultivo, la minería y las ciudades coloniales, debido a la prioridad absoluta concedida por los nuevos colonos a la ganadería, al cultivo de cereales, a la extracción de plata y al desarrollo urbano. ${ }^{36}$

Los españoles llegaron a la región altiplánica en 1533, abriendo nuevas tierras a la expansión europea, convirtiéndose el altiplano en espacio que no tardaría en ser ocupado parcialmente por los ganados y plantas traídas de la Península lbérica como el ganado ovino, la cebada o las habas, que eran Ios alimentos y recursos habitualmente consumidos por los europeos. Asimismo, algunos alimentos endógenos del altiplano serían exportados a Europa como la papa. ${ }^{37}$

El altiplano se convirtió en un buen productor de tejidos de ovino, hechos en los obrajes por los indios como tributo, que eran orientados hacia su venta principalmente a los trabajadores indígenas de las minas de plata del Potosí. Esta demanda hizo necesario transformar grandes extensiones de tierras agrícolas en pastizales, de tal manera, que la agricultura de excedencia fue paulatinamente dejada de lado, transformándose sólo en agricultura de subsistencia. ${ }^{38}$ La población de camélidos sudamericanos disminuyó rápidamente en el siglo XVI debido a una serie de consecuencias provocadas por la invasión española, como son la matanza, la manipulación en la forma de gestión y conservación tradicional de los camélidos y la introducción del ganado ovino. Así, el altiplano pasó de ser agrícola y ganadero a ser eminentemente ganadero y minero, ofreciendo principalmente tejidos y plata y trasmutando de una sociedad agropecuaria a una sociedad mercantilista. Al comienzo de la colonia española se consideraba esta zona altamente poblada, ${ }^{39}$ productiva y "muy pudiente en comercio y minería por lo que estaban en condiciones de pagar sumas más crecidas de tributos", según un veedor del siglo XVI, que recomienda efectuar una Visita a la misma para ajustar los tributos indígenas. Tal visita fue cursada por Garci Diez de San Miguel en 1567, a pedido del presidente de la Audiencia de Lima, el licenciado Castro.

Dicho visitador constató que una de las características definidoras del territorio altiplánico era su densa población humana durante el siglo XVl; así, por ejemplo, sólo en el corregimiento de Chuchito llegó a cifrar más de 20.000 indígenas. ${ }^{40}$ Y, por otra visita, la de Fray Pedro Gutiérrez Flores, en 1574 , sabemos que había un millar de hombres en la provincia de Chuchito a quienes el visitador consideraba

\footnotetext{
${ }^{36}$ Chantal Caillavet "Las técnicas agrarias autóctonas y la remodelación colonial del paisaje en los Andes Septentrionales, siglo XVI", Ciencia, vida y espacio en Iberoamérica. (Madrid: Consejo Superior de Investigaciones Científicas, 1989), 124.

${ }^{37}$ Fernández Pérez Joaquín y Ignacio González Tascón, Ciencia, técnica y Estado en la España llustrada. (Madrid: Secretaria de Estado de universidades e investigación, 1990), 16. Tan sólo un siglo después de la colonización se pudo ver los resultados del contacto entre los dos mundos que separaba el Atlántico, en cuanto a la aclimatación de las plantas en América. Las plantas llevadas a Europa tardaron aún más.

${ }^{38}$ Según José de Acosta refiriéndose al Altiplano andino (Crónica del siglo XVI) :" Es tierra sana y la más poblada de las Indias, y la más rica por la abundancia de ganados que se crían bien, así los de Europa, ovejas, vacas, cabras, como de los de la tierra, que llaman guanacos y pacos; hay caza de perdices harta“. José de Acosta, (1591) Historia natural y moral de las Indias) (Barcelona: Imprenta de Layme Cendrat), 128.

${ }^{39}$ Según Cieza de León, el Collao es la mayor comarca de todo el Perú y las más poblada (p. 254). Sin embargo, el altiplano sufrió epidemias durante los siglos XVI y XVII, perơ fueron menos letales en Chuchito que en otras partes del Perú, quizás debido en gran parte a su hábitat de altura. Noble David Cook. Demographic collapse, Indian Peru 1520-1630, (New York: Cambridge University Press, 1981), 44-49. Por su numerosa población estuvieron obligados a enviar mayor número de hombres a Potosí que cualquier otra provincia obligada a la mita, 0 sea un total de 2.200 hombres por año. Pero esto no duró mucho, pues muchos hombres murieron, huyeron, o se quedaron en Potosí generando disminución en la población, que los censos rara vez reflejaron correctamente hasta que trascurrieron varias décadas, aumentando la carga sobre los que permanecieron en sus ayllus, quienes siguieron pagando sus tributos y cumpliendo con la mita. Norman Meiklejohn, (1988). La iglesia y los Lupacas durante la colonia (pp. 28-29).

${ }^{40}$ Garci D. de San Miguel, Visita hecha a la Provincia de Chuchito por Garci Diez de San Miguel en el año 1567. (Lima: Ediciones de la Casa de la Cultura del Perú, 1964), 64-66.
} 
ricos a causa de sùs rebaños (Sección Contaduría, Legajo 1787, fojas 79-112, Archivo General de Indias). Pero, paulatinamente se produjo la descapitalización del altiplano en población humana, así como en el número de camélidos. Estos fueron menguando poco a poco y los pobladores emigrando hacia las minas del Potosí y al sur y al oeste de Puno y Chuchito, donde se descubrieron ricas vetas de plata a mediados del siglo XVII. ${ }^{41}$

Pero aquellos visitadores españoles se sorprendieron de la abundancia de camélidos en la zona y no de las técnicas agrícolas autóctonas, lo cual es un indicador más de que la actividad predominante en el altiplano era la ganadería. ${ }^{42}$ La población indígena se hallaba dispersa por el territorio debido principalmente a la práctica de la ganadería expansiva, actividad que había sido privilegiada desde la dominación inka en el altiplano. La adaptación de los nuevos cultivos y animales traídos de Europa permitieron a la población indígena obtener los recursos con los que tributaba a la Corona Española. ${ }^{43}$ Así, la imposición económica hizo extender la crianza de ganado ovino principalmente en el altiplano, pues los productos endémicos de la zona eran "no comerciales" y solo servían para la subsistencia campesina. En 1545, se descubrieron los yacimientos de plata en Potosí, lo que marcó -como se acaba de ver- una serie de cambios en el sistema económico-social, en el trabajo y en la distribución demográfica altiplánica. Después de haber sido durante siglos una región que vivía de la agricultura, ganadería, la región del Collao se convirtió en el eje de una economía exportadora de metales preciosos, principalmente de plata (Del Pozo 28). Se requirió de gran cantidad de gente y los españoles aprovechando el trabajo mancomunado preincaico de la minka, pudieron explotar la minería de la zona. De esta manera, los españoles supieron utilizar los esquemas económicos y sociales precolombinos preexistentes y manipularlos para sus fines: el sistema de trabajo comunal de la minka, el sistema jerárquico precolombino de los kuracas, como intermediarios de los indígenas, para la obtención de los tributos.

Pero además, aquellos colonizadores recurrieron a mecanismos europeos de control político -los corregimientos- y a un mecanismo de control demográfico -las reducciones de indios-. Así, en el siglo XVIII, surgirían la intendencias como la de Puno con el objetivo de ejercer un mejor control político, legislativo, fiscal (cobro de tributos) y comercial. Y, por su parte, las reducciones estaban orientadas a concentrar a la población indígena en lugares específicos, lo que daría con el tiempo nacimiento a las comunidades campesinas. ${ }^{44}$ Desde estos poblados de indígenas tributaban con trabajo y con productos. En la colonia, el indígena altiplánico trabajaba para su autosubsistencia con intercambios recíprocos y para los requerimientos exportadores y mercantilistas de la metrópoli, extrayendo los minerales para la demanda externa y elaborando los tejidos para la demanda interna. La minería y el obraje fueron las actividades que por su intensidad modelaron el paisaje cultural colonial altiplánico por tres siglos con grandes pastizales y yacimientos mineros.

Durante la colonia, el paisaje altiplánico era fundamentalmente un pastizal, con grandes ciudades coloniales cercanas al lago Titicaca y muchas reducciones en el interior. Los suelos aptos para desarrollar agricultura bajo inundación, alrededor del lago Titicaca, fueron ocupados por las ciudades españolas y poco a poco quedó en el olvido el uso de los camellones o waru waru. El altiplano estaba muy poblado, lo que le daba mucha movilidad, ya que aumentaba la trashumancia, pues cada vez habían más mitayos con ganado, pero sin tierras que buscaban donde hacer pacer a sus animales. En los siglos XVII y XVIII, el principal subproducto era la lana y la producción de los tejedores era tan barata que podía competir con las telas importadas de España e Inglaterra, por lo que encontró siempre mercado de bienes acabados en el circuito comercial andino. ${ }^{45}$

\footnotetext{
${ }^{41}$ Norman Meiklejohn, La iglesia y los Lupacas durante la colonia. (Cuzco: Centro de estudios rurales andinos Bartolomé de las Casas e Instituto de Estudios Aymaras, 1988), 34.

${ }^{42}$ San Miguel, 64.

${ }^{43}$ Fernández P. Joaquín y Ignacio González Tascón, Ciencia, técnica y Estado en la España llustrada, 1990, 15.

${ }^{44}$ Waldemar Espinoza Soriano, La destrucción del imperio de los Incas: la rivalidad política de los curacazgos andinos, (Lima: Amaru Editores, 1981), 158.

${ }^{45}$ Ethel Del Pozo-Verges, De la Hacienda a la mundialización. Sociedad, pastores y cambios en el altiplano peruano, (Lima: Instituto Francés de Estudios.Andinos, 2004), 35.
} 


\section{Fase 6: Apropiación y mixtura (1.821 d.C. a 2000). Republica: paisaje de pastizales, ciudades, desertificación y contaminación}

El paisaje continúa siendo eminentemente de pastizales y orientado a actividades ganaderas con ganado ovino y camélidos sudamericanos. Se potencia la agricultura con el rescate de tecnología agrícola precolombina como los camellones y los andenes. El paisaje recoge el producto del proceso de apropiación y mixtura de técnicas agropecuarias autóctonas y foráneas.

Según se ha venido viendo, al comienzo de esta fase iniciada con la república, el manejo del espacio altiplánico era eminentemente ganadero, en un territorio de grandes pastizales donde la agricultura era sólo de subsistencia dentro de latifundios cuya primera función era la de producir mercancías destinadas a la exportación de lana de oveja y fibra de alpaca. Así, la modelación del paisaje estaba fuertemente ligada a la estructura económica y política de carácter colonial que hasta entonces había imperado.

Esta fase republicana puede quedar subdividida en tres subfases o épocas: la de las grandes haciendas y el latifundio; la de la reforma agraria y sus empresas asociativas y la de la actual globalización.

La época de las haciendas y el latifundio que duró desde 1824 hasta 1969, siguió dando prioridad a la ganadería, de manera que la agricultura -con algunas excepciones- apenas fue practicada. Con la independencia, vinieron las ideas liberales de propiedad individual, que no concordaban con la propiedad colectiva tradicional indígena. A partir de 1834 sólo se exportaba lana de oveja y fibra de alpaca y vicuña como materia prima a Inglaterra, destinándose toda la producida para este fin, lo que supuso la ruina de la manufactura textil altoandina, que en la colonia había sido muy próspera. La venta de fibra de lana alcanzó su apogeo en 1874, con la construcción del ferrocarril que unía Puno y Arequipa que le daba acceso directo al mar. Desde entonces, el desarrollo se concentró en los pueblos cercanos a la vía férrea, condenando al aislamiento a los pueblos más alejados de aquella.

Entre 1895 y 1919 -periodo conocido como Republica Aristocrática- la oligarquía terrateniente peruana llegó al poder político y el latifundio en el altiplano se expandió, porque se produjo la expropiación de las tierras de las comunidades indígenas y la compra de las haciendas de la Iglesia Católica y de algunos pequeños propietarios.

A principios del siglo XX, la ganadería continuaba siendo la actividad principal y fue tanta que se consolidó un nuevo grupo social, ya existente en la colonia, de pastores sin tierras pero propietarios de ganado, constituyendo una muestra de un fenómeno social propio de una sociedad latifundista y dedicada a la ganadería: Ios huacchilleros, que se mantienen aún hoy. ${ }^{46}$

\section{Conclusión}

A modo de conclusión del presente artículo se podría indicar que una perspectiva que considera a la naturaleza "adaptativa" o con capacidad de adoptar diferentes estados, en el que ninguno es mejor a otro, proponiendo una gestión dinámica y cambiante, que se ajuste a la propia naturaleza, y desarrolle capacidades adaptativas a los cambios es la que mejor se adaptaría al medioambiente altiplánico. Esta fue la perspectiva aplicada por algunas culturas precolombinas altiplánicas que aprendieron, en un secular proceso de éxitos y fracasos, a efectuar un manejo complementario y transversal de ecosistemas naturales y técnicas hidráulicas y agropecuarias.

Las comunidades precolombinas desarrollaron mecanismos, criterios y objetivos para funcionar u otorgar capacidades adaptativas a una naturaleza, que al ser incierta, necesitaba de una "gestión adaptativa al cambio". Algunas culturas precolombinas coevolucionaban con el ambiente, iban adaptándose a los cambios en continua retroalimentación y en una dinámica no lineal. Tuvieron la capacidad de aprender de la experiencia e ir incorporando lo aprendido como capital acumulativo del

\footnotetext{
${ }^{46}$ Del Pozo-Verges, 43.
} 
sistema y ello les fùe permitiendo tener una capacidad adaptativa, a través de la cooperación, la auto organización y los saberes ecológicos tradicionales.

La aplicación de una estrategia proactiva o preventiva les fue permitiendo construir resiliencias en un mundo incierto y cambiante donde los criterios de gestión tenían que ser asimismo cambiantes y adaptativos. Ejemplos de paisajes antiguos de capacidad adaptativa a los cambios en el altiplano andino peruano serían los camellones, las cochas, los bofedales artificiales y los andenes o terrazas. 